\title{
Honouring Sir Stewart and his Work
}

The April edition of the British Journal of Ophthalmology, over which Sir Stewart Duke-Elder presided from 1948 to 1973 , is a Festschrift in his honour. It provides an opportunity to gather together a token of thanks from the ophthalmologists who worked in his newly founded Institute of Ophthalmology as trainees in the immediate post-war years. The contributors are largely limited to this group and they offer gratitude not only from themselves but on behalf of those whose life-work lies in the field of ophthalmology and who are therefore in some measure in debt to him through his encyclopaedic writings, bearing in mind that "only on paper has humanity yet achieved glory, beauty, truth, knowledge, virtue, and abiding love."

This number is also a mark of affection in remembrance of his many kindnesses and for the encouragement he bestowed on his younger colleagues in the long ago. We feel sure that ophthalmologists everywhere will share with Stewart and his wife Phyllis the happiness of his 76 th birthday which falls in April of 1974 and all will wish them well. 


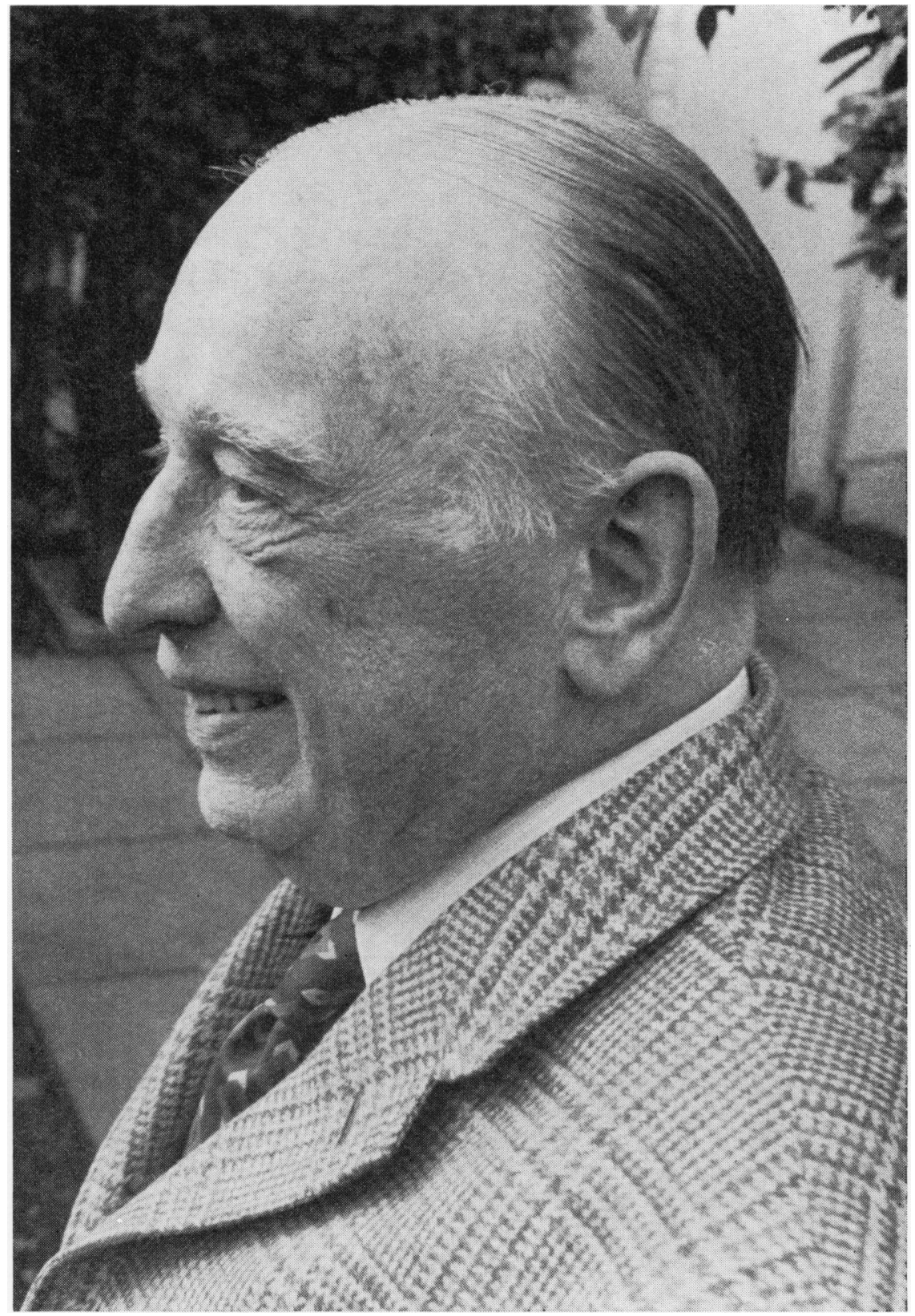

Sir Stewart Duke-Elder, G.C.V.O., F.R.S., taken by Paul Henkind in Fuly 1973 